ГИДРОГЕОЛОГИЯ, ГЕОЭКОЛОГИЯ

УДК 556.3

DOI: https://doi.org/10.17308/geology.2020.2/2862

ISSN 1609-0691

Поступила в редакцию: 13.05 .2020

Принята к публликации: 01.06 .2020

Опубликована онлайн: 30.06 .2020

\title{
Система экологического менеджмента состояния неоген-четвертичного и верхнедевонского водоносных комплексов территории Липецкой области
}

\author{
(2020 И. И. Косинова, Р. А. Ляпин \\ Воронежский государственный университет, \\ Университетская пл., 1, 394018, Воронеж, Российская Федерация
}

\begin{abstract}
Аннотация
Введение: Загрязнение подземных вод нитрат-ионами является одной из ведущих проблем на территориях городских агломераций. На территории Липецкой области расположено большое количество промышленных и сельскохозяйственных предприятий, которые обслуживают не только данную область, то и близлежащие регионы. Целью данной работы является построение системы экологического менеджмента состояния подземных вод Липецкой области, подверженных нитратному загрязнению.
\end{abstract}

Методика: Липецкая область располагается на стыке Среднерусской возвышенности и Окско-Донской низменности. По условиям залегания эксплуатационные водоносные комплексы Липецкой области подразделяются на порово-пластовые неоген-четвертичного водоносного комплекса и трещинно-карстовые верхнедевонского водоносного комплекса. В процессе выполнения работы было проведено эколого-гидрогеохимическое районирование территории Липецкой области по уровню экологического благополучия, основанное на степени загрязнения подземных вод неоген-четвертичного и верхнедевонского водоносных комплексов Липецкой области нитратами, с выделением трех категорий участков, отличающихся допустимым, умеренно-опасным и опасным уровнем экологического неблагополучия. На основе данного районирование была построена система экологического менеджмента нитратного загрязнения подземных вод Липецкой области с финансовым обеспечением природоохранных. В основе данной работы лежит информация по кадастру скважин подземных вод Липецкой области за 2017 г.

Результаты и обсуждение: Для водоносных комплексов содержание нитратов выше предельнодопустимых значений составляет от 45 мг/дм ${ }^{3}$ до 135 мг/дм². Можно утверждать, что оба комплекса загрязнены в равной степени, вследствие отсутствия регионального водоупора и бурного развития техногенной деятельности вблизи крупных городских поселений. Итоговая сумма природоохранных мероприятий составила около 7 миллиардов 600 миллионов рублей, 5.5 миллиардов из которых планируется выделить из федерального бюджета Липецкой, а также 2.1 миллиарда рублей потратятся за счет средств коммерческих организаций, являющимися источниками загрязнения нитратами.

Заключение: По истечению десятилетнего периода выполнения программы системы экологического менеджмента необходимо оценить процесс модернизации оборудования на предприятиях и изменения количественного состава нитратов в подземных водах. В случае отсутствия положительной тенденции в сторону уменьшения концентрации нитратов в подземных водах эксплуатационных водоносных комплексов пересмотреть систему экологического менеджмента.

Ключевые слова: Подземные воды, водоносный комплекс, нитраты, загрязнение, система экологического менеджмента.

Контент доступен под лицензией Creative Commons Attribution 4.0 License.

Ляпин Роман Андреевич, e-mail: lyapin.roman@yandex.ru 
Для циитирования: Косинова И. И., Ляпин Р. А. Система экологического менеджмента состояния неогенчетвертичного и верхнедевонского водоносных комплексов территории Липецкой области // Вестник Воронежского государственного университета. Серия: Геология. $2020 . \quad$ №2. С. 83-89. DOI: https://doi.org/10.17308/geology.2020.2/2862

\section{Введение}

Загрязнение подземных вод нитрат-ионами является одной из ведущих проблем на территориях городских агломераций. На территории Липецкой области расположено большое количество промышленных и сельскохозяйственных предприятий, которые обслуживают не только данную область, то и близлежащие регионы.

Объектом исследования в настоящей работе являются водоносные комплексы территории Липецкой области.

Предмет исследования представляет собой анализ влияние техногенной нагрузки на подземные воды территории Липецкой области.

Целью данной работы является построение системы экологического менеджмента состояния подземных вод Липецкой области, подверженных нитратному загрязнению.

\section{Методика}

Земная поверхность территории Липецкой области представляет собой возвышенную волнистую равнину, расчлененную долинами рек, балками и оврагами. Липецкая область располагается на стыке Среднерусской возвышенности и Окско-Донской низменности. Граница между ними в пределах области проходит по долинам рек Воронежа и Становой Рясы. Большую часть области занимает денудационная равнина с преобладанием новейших поднятий; меньшую - юговосточную часть - аккумулятивная равнина, созданная преимущественно новейшими опусканиями. Основная территория (примерно 75\%) - возвышенная равнина.

По условиям залегания эксплуатационные водоносные комплексы Липецкой области подразделяются на порово-пластовые неоген-четвертичного водоносного комплекса и трещинно-карстовые верхнедевонского водоносного комплекса. Неоген-четвертичный водоносный комплекс (N-Q), который эксплуатируется в юго-восточной и восточной части Липецкой области в районе Окско-Донской низменности, состоит из множества регионально развитых или локальных горизонтов. Вмещающими породами данного комплекса являются песчано-глинистые породы мощностью до 200 м. Под N-Q водоносным комплексом повсеместно залегает верхнедевонский комплекс, который является главным водоносным комплексом при эксплуатации подземных вод на территории области.

Верхнедевонский водоносный комплекс включает в себя 3 горизонта: верхнефаменский, задонско-елецкий и евлановско-ливенский.
Верхнефаменский горизонт $\left(\mathrm{D}_{3} \mathrm{fm}_{2}\right)$ эксплуатируется в северной части Липецкой области. Водоносный комплекс представлен известняками с прослоями глин и мергелей. Общая мощность горизонта достигает 40 м.

Задонско-елецкий горизонт $\left(\mathrm{D}_{3} \mathrm{zd}-\mathrm{el}\right)$, который занимает центральную часть Липецкой области, представлен брекчеевидными известняками, с прослоями глин и конгломератов. Мощность комплекса достигает $80 \mathrm{M}$.

Евлановско-ливенский водоносный горизонт $\left(\mathrm{D}_{3} \mathrm{ev}-\mathrm{lv}\right)$, расположенный в юго-западной части Липецкой области, сложен известняками органического происхождения с прослоями мергелей и глин. Общая мощность комплекса - $100 \mathrm{M}$.

По условиям залегания и составу подземных вод неоген-четвертичный и верхнедевонский водоносные комплексы удобны и благоприятны для использования в хозяйственно-питьевых целях. Доля участия в подземном питании этих комплексов неодинакова, а также они имеют отличия по водообильности.

Статический уровень подземных вод неоген-четвертичного водоносного комплекса составляет 5-15 м. Комплекс безнапорный, водообильность его хорошая. Запасы подземных вод формируются за счет инфильтрации атмосферных осадков. А в маловодные годы происходит подтягивание подземных вод нижележащих горизонтов верхнего девона, в частности подземных вод отложений задонско-елецкого возраста. Мощность слоя составляет 15-30 м. Водовмещающими породами комплекса являются мелко- и среднезернистые пески с примесью железа и прослоями глин в подошве.

Глубина залегания подземных вод верхнедевонского водоносного комплекса составляет от 122 м до 237 м. Данный комплекс является основным при эксплуатации подземных вод Липецкой области. Верхнедевонский водоносный комплекс имеют прямую связь с питанием рек Липецкой области. Так, задонско-елецкий и лебедянский горизонты участвуют в питании реки Воронеж в летний и зимний периоды. Водовмещающими породами комплекса являются известняки с прослоями глин и мергелей. Главным водоносным комплексом Липецкой области является верхнедевонский, тогда как воды неоген-четвертичного водоносного комплекса эксплуатируются только в юго-восточной и восточной части Липецкой области, что составляет порядка 10-12\% от общего количества добываемых вод. Благодаря наличию вмещающих песчано-глинистых пород верхнедевонский водоносный комплекс подвергается меньшей угрозе от антропогенного загрязнения нитратами. В верхнедевонских отложениях территории наиболее распространены процессы углекислотного выщелачивания, катионного обмена. В результате трещинноватости известняков елецкого и задонского возраста подземные воды характеризуются недостаточной защищенностью, что является причиной их загрязнения нитратами.

На территории Липецкой области расположено 
большое количество предприятий, которые обслуживают не только данную область, то и близлежащие регионы. Из самых распространенных производств можно выделить птицефабрики, сахарные заводы, металлургический холдинг, заводы строительных материалов, заводы по розливу минеральных вод, предприятия машиностроения и металлообработки. Наибольшее скопление промышленных предприятий приурочено к двум крупнейшим городам области - Липецку и Ельцу. На основании большого спектра предприятий промышленного и сельскохозяйственного комплексов можно сделать вывод, что уровень техногенной нагрузки Липецкой области можно оценить, как существенный.

Экологические аспекты, влияющие на нитратное загрязнение подземных вод Липецкой области, можно подразделить по их происхождению на природные и техногенные. Карта-схема расположения водоносных комплексов территории Липецкой области представлена на рис.1.

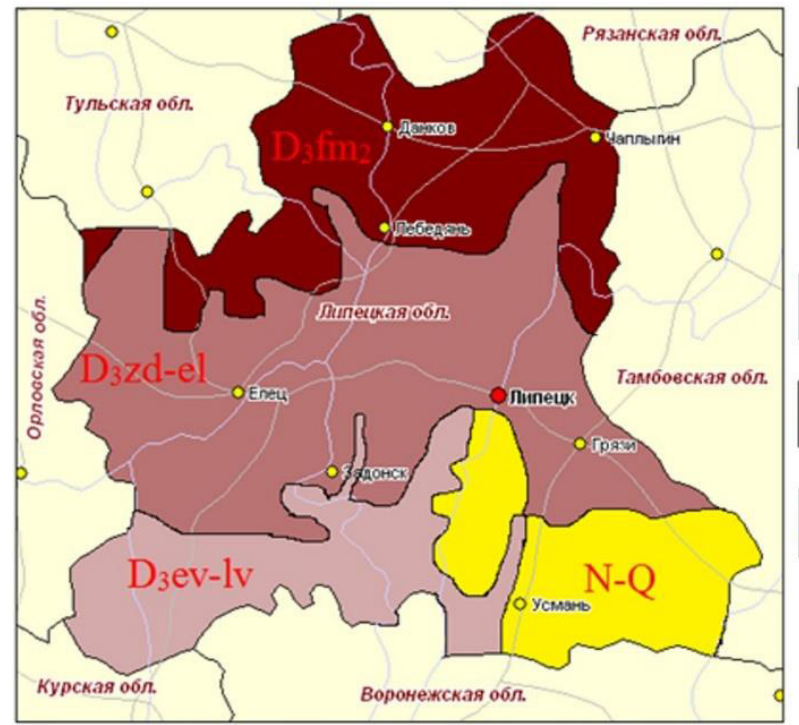

\section{Условные обозначения}

N-Q Неоген-четвертичный водоносный комплекс

\section{Верхнедевонский водоносный комплекс}

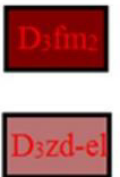

Верхнефаменский водоносный горизонт

Задонско-елецкий водоносный горизонт

\section{Dзev-ly Евлановско-ливенский водоносный} горизонт

Рис. 1. Карта-схема расположения водоносных горизонтов территории Липецкой области.

[Fig.1. Map of the location of aquifers in the Lipetsk region.]

Источники, влияющие на нитратное загрязнение подземных вод Липецкой области, можно подразделить по их происхождению на природные и техногенные. К природным факторам относят слабую защищенность водоносных горизонтов и наличие овражно-балочной сети. Техногенными источниками являются промышленные предприятия (металлургия, машиностроение и металлообработка, химические и нефтехимические производства), агропромышленный сектор (птицефабрики, животноводческие комплексы, заводы пищевой промышленности), коммунально-бытовой сектор (коммунальные предприятия сельской местности), отходы производства (полигоны захоронения отходов, поля захоронения и поля ядохимикатов).

Максимальные концентрации нитратов в очагах установлены в пониженных частях рельефа - бортах оврагов и балках, которые сложены трещиноватыми известняками и характеризуются карстовыми проявлениями.

В процессе выполнения работы было проведено эколого-гидрогеохимическое районирование территории Липецкой области по уровню экологического благополучия, основанное на степени загрязнения подземных вод неоген-четвертичного и верхнедевонского водоносных комплексов Липецкой области нитратами, с выделением трех категорий участков, отличающихся допустимым, умеренно-опасным и опасным уровнем экологического неблагополучия. На основе данного районирование была построена система экологического менеджмента (СЭМ) нитратного загрязнения подземных вод Липецкой области с финансовым обеспечением природоохранных мероприятий.

В основе данной работы лежит информация по кадастру скважин подземных вод Липецкой области за 2017 г., куда включены данные о веществах-загрязнителях подземных вод за период с 2005 по 2017 гг. На территории Липецкой области пробурено 4241 скважина, в 410 из которых эксплуатируемых водоносный комплекс - неоген-четвертичный, в остальных - верхнедевонский. Кадастровые данные, предоставленные Управлением экологии и природных ресурсов Липецкой области, фрагментарны и не постоянны во времени.

\section{Обсуждение результатов}

Для решения поставленной задачи было произведено эколого-гидрогеохимическое районирование территории Липецкой области по уровню экологического благополучия на основе загрязнения эксплуатационных водоносных комплексов (неоген-четвертичного и верхнедевонского) нитратами (рис. 2).

На основании картографических интерполяционных моделей территория Липецкой области по уровню 


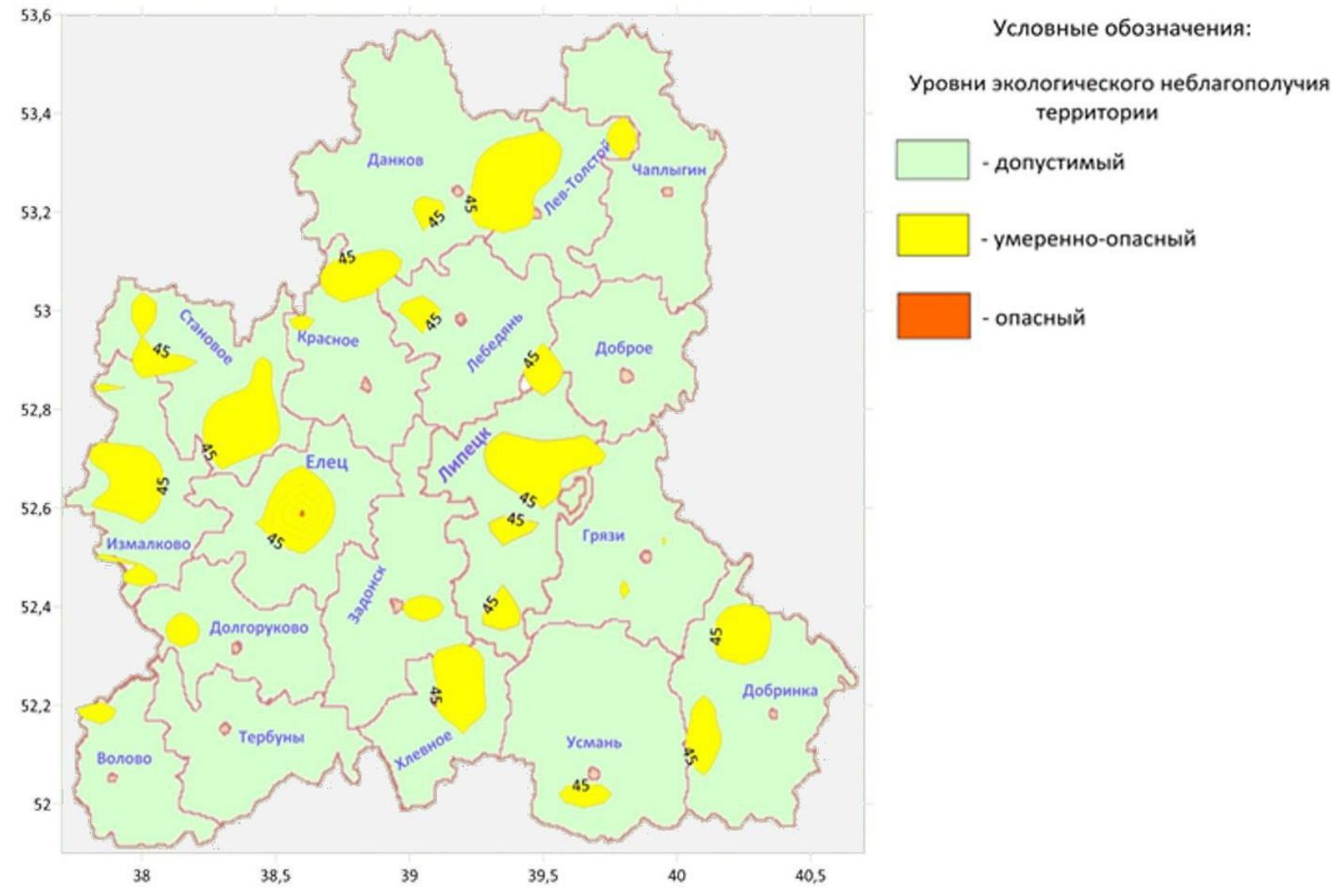

Рис. 2. Карта-схема эколого-гидрогеохимического районирования территории по уровню нитратного загрязнения подземных вод неоген-четвертичного и верхнедевонского водоносных комплексов территории Липецкой области на 2017 г.

[Fig. 2. Map-scheme of ecological and hydrogeochemical zoning of the territory by the level of nitrate pollution of underground waters of the Neogene-Quaternary and upper Devonian aquifers of the Lipetsk region for 2017.]

экологического благополучия разделена на три зоны:

- допустимый уровень экологического неблагополучия (около 65\% территории) с концентрацией нитратов менее 45 мг/дм ${ }^{3}$;

- умеренно-опасный уровень экологического неблагополучия (около 34\% территории) с превышением нитратов составляет от 1 до 5 ПДК (45-225 мг/дм³);

- опасный уровень экологического неблагополучия (около 1\% территории - южнее города Елец) с превышением нитратов более 5 ПДК (225 мг/дм $\left.{ }^{3}\right)$.

В целом, уровень нитратного загрязнения колеблется от 1 до 10 ПДК.

На рис. 2 представлена карта-схема эколого-гидрогеохимического районирования территории по уровню нитратного загрязнения подземных вод неоген-четвертичного и верхнедевонского водоносных комплексов территории Липецкой области на 2017 г.

Для верхнедевонского водоносного комплекса среднее значение концентрации нитратов выше ПДК варьирует от 45 мг/дм ${ }^{3}$ до 135 мг/дм ${ }^{3}$ (от 1 до 3 ПДК) с преобладающим значением в 1.5 ПДК. Факторами загрязнения подземных вод здесь являются сельскохозяйственные и промышленные предприятия, неочищенные коммунально-бытовые стоки, складирование отходов.

Большему влиянию загрязнения нитратами подвержены верхнефаменский и особенно задонско-елецкий водоносные горизонты, в меньшей степени - воды евлановско-ливенского горизонта, вследствие наличия глинистых известняков. Территории, где эксплуатируются воды задонско-елецкого горизонта, отличаются большим уровнем урбанизации территории по сравнению с другими участками. Максимальные значения концентрации нитратов более 225 мг/дм ${ }^{3}$ (свыше 5 ПДК) зафиксированы в виде аномалии южнее города Елец в задонско-елецком водоносном горизонте, в связи с многолетним складированием отходов в овражно-балочную сеть и наличием птицефабрики.

Территории восточной и юго-восточной части Липецкой области благодаря наличию вмещающих песчано-глинистых пород неоген-четвертичного возраста характеризуются значениями нитратов в подземных водах ниже ПДК. Для данного комплекса среднее значение концентрации нитратов выше ПДК также варьируется от 45 мг/дм ${ }^{3}$ до 135 мг/дм ${ }^{3}$ (от 1 до 3 ПДК) с преобладающим значением в 1.5-2 ПДК. Источником загрязнения здесь является деятельность Добринского сахарного завода.

Для обоих водоносных комплексов содержание нитратов выше ПДК составляет от 45 мг/дм ${ }^{3}$ до 135 мг/дм ${ }^{3}$. Можно утверждать, что оба водоносных комплекса загрязнены в равной степени, вследствие отсутствия регионального водоупора и бурного развития 
техногенной деятельности вблизи крупных городских поселений.

На основе проведенного районирования построена система экологического менеджмента состояния эксплуатируемых водоносных комплексов Липецкой области, включающая спектр мероприятий по постоянному улучшению их состояния:

1. Вывоз ТКО из овражно-балочной сети Елецкого района и их утилизация.

2. Переработка куриного помета в органическое удобрение.

3. Биохимическая очистка сточных вод металлургических предприятий.

4. Реконструкция очистных сооружений.

5. Очистка подземных вод из скважин с превышением ПДК по нитратам в 3 раза и более.

На первом этапе необходимо внедрить СЭМ в зонах максимального влияния техногенной деятельности - Липецком, Елецком, Добринском, Измалковском, Лев-Толстовском, Становлянском, Данковском районах. А далее на территориях, подверженных меньшему влиянию техногенной деятельности, а именно Лебедянскому, Хлевенскому, Задонскому, Краснинскому районах.

На основании выполненных расчетов итоговая сумма природоохранных мероприятий составила около 7 миллиардов 600 миллионов рублей, 5.5 миллиардов из которых планируется выделить из федерального бюджета Липецкой области на вывоз ТКО из овражно-балочной сети Елецкого района, их утилизацию и реконструкцию очистных сооружений, а также 2.1 миллиарда рублей потратятся за счет средств коммерческих организаций, являющимися источниками загрязнения нитратами, куда входит очистка подземных вод из скважин, биохимическая очистка сточных вод, переработка куриного помета в органическое удобрение. Также можно получить финансовую поддержку за счет средств Фонда содействия реформированию ЖКХ, энергоэффективности и экологии Липецкой области.

\section{Заключение}

На основании проведенных исследований были сделаны следующие выводы.

1. Эколого-геологические условия Липецкой области оцениваются как благоприятные. Это обусловлено благоприятными природными условиями, спокойным рельефом, богатыми запасами поверхностных и подземных вод.

2. Источники загрязнения нитратами подземных вод Липецкой области можно разделить на несколько видов: природные и техногенные. Природные источники - слабая защищенность водоносных горизонтов и наличие овражно-балочной сети. К техногенным источникам относятся:

Агропромышленный комплекс - птицефабрики, животноводческие комплексы, заводы пищевой промышленности.

Промышленные предприятия - металлургия, маши- ностроение и металлообработка, химические и нефтехимические производства, горнодобывающие предприятия.

Коммунально-бытовой сектор - комплексы очистки хоз-бытовых и ливневых вод, коммунальные предприятия сельской местности.

Отходы производства - полигоны захоронения отходов, поля захоронения и поля ядохимикатов.

3. На основании построенных картографических интерполяционных моделей территория Липецкой области разделена на три зоны: допустимый уровень экологического неблагополучия (около 65\% территории); умеренно-опасный уровень экологического неблагополучия (около 34\% территории); опасный уровень экологического неблагополучия (около 1\% территории - южнее города Елец). На основе проведенного районирования построена система экологического менеджмента, включающая комплекс мероприятий по улучшению состояния водоносных комплексов, куда входит вывоз ТКО из овражно-балочной сети Елецкого района, их утилизация и реконструкция очистных сооружений, очистка подземных вод из скважин, биохимическая очистка сточных вод, переработка куриного помета в органическое удобрение. Итоговая сумма природоохранных мероприятий составила около 7 миллиардов 600 миллионов.

Конфликт интересов: Авторы декларируют отсутствие явных и потенциальных конфликтов интересов, связанных с публикацией настоящей статьи.

\section{ЛИТЕРАТУРА}

1. Прудовский Э. Л. Количественное и качественное состояние подземных вод Липецкой области. Ф. Липецк. Липецкий филиал ФГУ ТФИ, 2007. 58 с.

2. Дюнин В. И. Отчет о результатах изучения загрязнения нитратами подземных вод на водозаборах г. Липецка, расчет зон санитарной охраны и разработка рекомендации по ликвидации нитратного загрязнения. Ф. Липецк. Липецкий филиал ФГУ «Геоинфотека», 2001. 68 с.

3. Прудовский Э. Л. Выявление причин и источников загрязнения нитратами подземных вод в Липецкой области. Ф. Липецк. Липецкий филиал ФГУ ТФИ, 2006. 71 с.

4. Косинова И. И., Белозеров Д. А. Менеджмент в экологии: учебно-методическое пособие для бакалавров, обучающихся по направлению 05.03.01 «Геология». Воронеж, Научная книга. 2017. 75 с.

5. Методика «Критерии оценки экологической обстановки территорий для выявления зон чрезвычайной экологической ситуации и зон экологического бедствия», утвержденная Минприроды РФ 30.11.1992. 109 с.

6. Косинова И. И., Кустова Н. Р. Теория и методология геоэкологических рисков // Вестник Воронежского государственного университета. Серия: Геология. 2008. № 2. С. 189-197.

7. Базарский О. В., Косинова И. И., Фонова С. И. Математическое моделирование загрязнения приповерхностных отложений аэрозольными частицами // Инженерные изыскания. 2015. № 5-6. С. 76-79.

8. Базарский О. В., Косинова И. И. О единой метрике комплексного эколого-геологического пространства. Вестник Воронежского государственного университета. Серия: Геология. 2005. № 2. С. 168-172. 


\title{
The environmental management system of the Neogene-Quaternary and Upper Devonian aquifers in the Lipetsk region
}

\author{
(C2020 I. I. Kosinova, R. A. Lyapin ${ }^{凶}$ \\ Voronezh State University, \\ 1 Universitetskaya pl., Voronezh 394018, Russian Federation
}

\begin{abstract}
Introduction: Groundwater pollution by nitrate ions is one of the leading issues in urban agglomerations. Within the territory of the Lipetsk region there are a large number of industrial and agricultural enterprises that serve not only this region, but also the neighbouring regions. The aim of this study is to build an environmental management system for groundwater in the Lipetsk region that is subject to nitrate pollution. Methodology: The Lipetsk region is located at the joint of the Central Russian Upland and the Oka-Don Lowland. According to the conditions of their occurrence, the operating aquifers of the Lipetsk region are divided into pore-stratal aquifers in the Neogene-Quaternary aquifer system and fissure-karst aquifers in the Upper Devonian aquifer system. In the course of the study, ecological and hydrogeochemical zoning of the territory of the Lipetsk region was carried out according the level of environmental well-being. It was based on the level of nitrate pollution of the groundwater in the Neogene-Quaternary and the Upper Devonian aquifers in the Lipetsk region. Three categories of zones were distinguished, with an acceptable, moderately dangerous, and dangerous level of environmental trouble. Based on this zoning, an environmental management system was designed to control nitrate pollution of groundwater in the Lipetsk region with financial support for environmental protection. The study is based on the information from the cadastre of groundwater wells in the Lipetsk region for 2017.

Results and discussion: For both aquifers, the nitrate content is above the maximum permissible values, it ranges from $45 \mathrm{mg} / \mathrm{dm}^{3}$ to $135 \mathrm{mg} / \mathrm{dm}^{3}$. We can say that both of them are equally polluted due to the lack of regional aquiclude and the rapid development of technogenic activity near large urban areas. The total cost of the environmental protection measures amounted to about 7 billion 600 million roubles, of which 5.5 billion are to be allocated from the federal budget to the Lipetsk region, and 2.1 billion roubles will be provided by commercial organisations that cause nitrate pollution.

Conclusions: Upon the expiry of a ten-year period for the implementation of the environmental management system program, we should evaluate the process of equipment modernization at enterprises and changes in the quantitative composition of nitrates in groundwater. If there is no positive tendency towards a decrease in the concentration of nitrates in the groundwater of the aquifers, it will be necessary to review the environmental management system.
\end{abstract}

Keywords: Groundwater, aquifers, nitrates, pollution, environmental management system.

For citation: Kosinova I. I., Lyapin R. A. The environmental management system of the Neogene-Quaternary and Upper Devonian aquifers in the Lipetsk region. Vestnik Voronezhskogo gosudarstvennogo universiteta. Seriya: Geologiya = Proceedings of Voronezh State University. Series: Geology. 2020. No. 2. pp. 83-89. DOI: https://doi.org/10.17308/geology.2020.2/2862

The content is available under Creative Commons Attribution 4.0 License.

\footnotetext{
Roman A. Lyapin, e-mail: lyapin.roman@yandex.ru
} 
Conflict of interests: The authors declare the absence of obvious and potential conflicts of interest related to the publication of this article.

\section{REFERENCES}

1. Prudovsky E. L. Kolichestvennoe i kachestvennoe sostoyanie podzemnykh vod Lipetskoi oblasti. [Quantitative and qualitative state of underground waters of the Lipetsk region]. F. Lipetsk, Lipetsk branch of FSU TFI, 2007, 58 p. (In Russ.).

2. Dunin V. I. Otchet o rezul'tatakh izucheniya zagryazneniya nitratami podzemnykh vod na vodozaborakh g. Lipetska, raschet zon sanitarnoi okhrany $i$ razrabotka rekomendatsii po likvidatsii nitratnogo zagryazneniya. [Report on the results of the study of nitrate contamination of underground water at water intakes in Lipetsk, calculation of sanitary protection zones and development of recommendations for the elimination of nitrate pollution]. F. Lipetsk: Lipetsk branch of the Federal State University "Geoinfoteka" publ., 2001, 68 p. (In Russ.).

3. Prudovsky E. L. Vyyavlenie prichin i istochnikov zagryazneniya nitratami podzemnykh vod $v$ Lipetskoi oblasti. [Identification of causes and sources of nitrate pollution of underground water in the Lipetsk region]. F. Lipetsk, Lipetsk branch of FSU TFI, 200, 71 p. (In Russ.).

4. Kosinova I. I., Belozerov D. A. Menedzhment v ekologii: uchebno-metodicheskoe posobie dlya bakalavrov, obuchayushchikhsya po napravleniyu 05.03.01 «Geologiya». [Management in ecology: educational and methodological guide for bachelors studying in the direction 05.03.01 "Geology"]. Voronezh, Scientific book publ., 2017, 75 p. (In Russ.).

5. Metodika «Kriterii otsenki ekologicheskoi obstanovki territorii dlya vyyavleniya zon chrezvychainoi ekologicheskoi situatsii $i$ zon ekologicheskogo bedstviya», [Methodology «Criteria for assessing the environmental situation of territories to identify areas of environmental emergency and disaster zones»], approved by the Ministry of natural resources of the Russian Federation 30.11.1992, 109 p. (In Russ.).

6. Kosinova I. I., Kustova N. R. Theory and methodology of geo-ecological risks. Vestnik Voronezhskogo gosudarstvennogo universiteta. Seriya: Geologiya $=$ Proceedings of Voronezh State University. Series: Geology. 2008. no. 2, pp. 189-197. (In Russ.). 7. Bazarsky O. B., Kosinova I. I., Fonova S. I. Matematicheskoe modelirovanie zagryazneniya pripoverkhnostnykh otlozhenii aerozol'nymi chastitsami. [Mathematical modeling of contamination of near-surface deposits by aerosol particles]. Inzhenernye izyskaniya = Engineering survey. 2015. no. 5-6, pp. 76-79. (In Russ.).

8. Bazarsky O. V., Kosinova I. I. On the unified metric of complex ecological and geological space. Vestnik Voronezhskogo gosudarstvennogo universiteta. Seriya: Geologiya = Proceedings of Voronezh State University. Series: Geology. 2005. no. 2, pp. 168-172. (In Russ.).
Косинова Ирина Ивановна - д.г.-м.н., профессор, Воронежский государственный университет, Воронеж, Российская Федерация; E-mail: Kosinova777@yandex.ru; ORCID http://orcid.org/0000-0002-5439-5197

Ляпин Роман Андреевич - аспирант, Воронежский государственный университет, Воронеж, Российская Федерация; Еmail: lyapin.roman@yandex.ru;

ORCID http://orcid.org/0000-0003-0562-4261

Авторы прочитали и одобрили окончательный вариант рукописи.
Irina I. Kosinova - PhD, Dr. habil. in Geol.-Min., Professor, Voronezh state University, Voronezh, Russian Federation; Email: Kosinova777@yandex.ru; ORCID http://orcid.org/0000-0002-5439-5197

Roman A. Lyapin - postgraduate student, Voronezh state University, Voronezh, Russian Federation; E-mail: lyapin.roman@yandex.ru;

ORCID http://orcid.org/0000-0003-0562-4261

All authors have read and approved the final manuscript. 